\title{
VALOR, ESTRUCTURA Y SITUACIÓN
}

A pesar del evidente progreso que se advierte en la axiología de este siglo, no ha surgido aún una teoría satisfactoria sobre la naturaleza del valor. Por otra parte, persiste el desacuerdo sobre cuáles son los problemas fundamentales de la axiología. Los agudos análisis del positivismo lógico en un principio y de la filosofía analítica en época más reciente, han clarificado el problema axiológico si bien lo han derivado hacia cuestiones de menor importancia.

El problema central se mantiene en pie: ¿es el valor una cualidad o un ente? En cualquiera de los dos casos, ¿conferimos nosotros valor a las cosas o ellas nos lo imponen? En términos más tradicionales: ¿radica el valor en cualidades que se hallan en el objeto o en nuestras reacciones?

En nuestra América, donde las teorías filosóficas se convierten habitualmente en dogmas con ciegos defensores, el objetivismo absolutista y a priori tuvo fuerte tono dogmático durante muchos años. No quiere decir que no hayan existido entre nosotros doctrinas axiológicas heterodoxas -como las de Korn y Caso-, pero el predominio del objetivismo era patente. Max Scheler y, en menor medida, Nicolai Hartmann, eran los "descubridores" de la naturaleza objetiva y absoluta del valor y se los enseñaba como verdad indiscutible en cursos universitarios y manuales de filosofía.

\section{El objetivismo a priori de Scheler}

Si bien hemos analizado y expuesto críticamente, con anterioridad, la doctrina de Max Scheler, 1 será conveniente resumir las críticas fundamentales en este ensayo que tiende a superar la antítesis de objetivismo y subjetivismo, aunque recoge los hallazgos de una y otra teoría.

Para Scheler los valores son independientes de los bienes y de los sujetos que los valoran, por ser absolutos e inmutables. El sujeto capta los valores y no participa en su constitución; los bienes, a su vez, reciben los valores sin que logren modificarlos. Scheler es bien explícito sobre este punto. Escribe: "Ios valores existen con independencia de un ser espiritual determinado". 2 Y más adelante los compara con los números, que no suponen, a su juicio, la existencia de ningún yo.

Como adjudica al valor carácter de esencia a priori, se pone a reparo de cualquier crítica basada en la experiencia, por más reiterada que sea; la esencia mantiene su inmutabilidad. De este modo Scheler llega a afirmaciones tautológicas que son tan ciertas como infecundas. Dice, por ejemplo, que lo

1 Ver nuestra obra ${ }_{i} Q$ ué son los valores?, México, $\mathrm{FCE}, 1972,5^{\mathrm{a}}$ ed., cap. V.

2 Cf. Etica, $1^{\text {a }}$ ed., t. II, p. .33 . 
nutritivo es nutritivo aunque dañe la salud de muchas personas. Si bien la experiencia nos muestra que hay muchos alimentos que son nutritivos para algunas personas y dañinos para otras, Scheler insiste en su afirmación tautológica sin reparar en que la noción de "nutritivo" es el producto de la experiencia y se basa en la bioquímica más que en la axiología.

Como el ser del valor, para Scheler, es independiente del ser real, llega a afirmar: "Aunque nunca se hubiera 'juzgado' que el asesinato era malo, hubiera el asesinato sido malo. $\mathrm{Y}$ aun cuando el bien nunca hubiera 'valido' como 'bueno', sería, no obstante, bueno". 3

Si bien Scheler navega en el mundo de las esencias, fácil resulta mostrar que extrae dichas 'esencias' del mundo de su experiencia personal. Los valores que examina y considera como absolutos, a priori e inmutables, lo mismo que la jerarquía que enuncia, coinciden con lo predominante en su época, su país, su clase social, su grupo y su ambiente. Si hubiera nacido y se hubiera criado en la China del siglo xv, su axiologia sería distinta.

No es necesario realizar imaginativamente este cambio; basta lo ocurrido al propio Scheler. Como es sabido, dio a toda la escala axiológica un fundamento religioso, dentro de una concepción de un Dios personal, espiritual, infinito e inmutable. Tal concepción teológica era la garantía y fundamento de toda la jerarquía axiológica. Lo dice expresamente: "Todos los posibles valores se 'fundan' en el valor de un espiritu personal e infinito y de un 'universo de valores' que de aquél procede." 4 Pero, como es sabido, Scheler abandonó esa posición teológica al final de su vida. Desaparecido el fundamento, muy mal parada queda la jerarquía. Los valores y su jerarquía, que fueron definidos como absolutos e inmutables y que no dependían de ningún sujeto, tuvieron, sin embargo, que ajustarse a la nueva doctrina teológica de Scheler. La ingenuidad y soberbia filosóficas cedieron paso a una experiencia vital que arrasó los esquemas prefabricados. Scheler no se tomó el trabajo de rehacer su axiología para ajustarla a las nuevas ideas teológicas, seguramente porque hubiera implicado negar todas las afirmaciones básicas sostenidas dogmáticamente en su Etica.

No satisfecho con la mera enunciación de una jerarquía fija, que el lector no sabe de dónde proviene, Scheler ofrece cinco criterios para descubrir la altura relativa de un valor. Son, como se sabe, la durabilidad, la divisibilidad, la profundidad de la satisfacción, la fundación y la relatividad.

Además de estos criterios, que analizaremos críticamente, Scheler considera que en el preferir se nos da la jerarquía de los valores. Escribe: "el ser superior de un valor es 'dado' forzosa y esencialmente tan sólo en el preferir. ${ }^{5}$

Scheler siente la necesidad de recurrir a la experiencia para justificar su

3 Op. cit., I, p. 8 .

4 Op cit., I, p. 14 o.

5 lbid., p. 130. 
jerarquía axiológica a priori. No cree, desde luego, que la jerarquía dependa de nuestras preferencias; de lo contrario caería en el empirismo que había criticado y rechazado. Por medio del preferir captamos la superioridad de un valor sobre otro. Por otra parte, señala que el preferir se realiza sin ningún tender, elegir ni querer.

Parece difícil que la preferencia nos ofrezca un criterio seguro porque depende de las condiciones propias de cada sujeto: edad, sexo, educación, medio sociocultural. Las preferencias de Scheler son, en buena medida, germánicas, burguesas y académicas.

Mas, si las preferencias dependen de los sujetos y circunstancias, se producen conflictos preferenciales, como ocurre efectivamente. En tal caso, ¿qué preferencia debo preferir? La preferencia exige un criterio por encima de ella, capaz de resolver tales conflictos.

Las discrepancias no se deben tan sólo a diferencias de los sujetos; también dependen de los objetos. Cabe anotar, en primer lugar, que las preferencias no se refieren principalmente a los valores sino a los bienes, como lo muestran los propios ejemplos de Scheler. En tal caso, depende de otros factores, entre ellos la calidad de la realización del valor en el bien que preferimos. Por ejemplo, ¿debemos preferir un cuadro mediocre a un Rolls Royce porque el valor estético es superior? El hecho de que sea mediocre rebaja su nivel. En el propio ejemplo de Scheler - "prefiero la rosa al clavel"-, la preferencia dependerá del color, la forma, tipo, etc., de ambas flores. Una 'mala' rosa es inferior a un 'buen' clavel. Afirmar que se refiere a la rosa y al clavel en general es esquivar la dificultad, porque las rosas y los claveles no existen en general.

Como puede advertirse, la preferencia implica un complejo mecanismo psicológico que depende del sujeto, sus condiciones socioculturales y los modos en que el valor se presenta encarnado en el bien. La complejidad empaña la supuesta seguridad de la preferencia como forma reveladora de la jerarquia axiológica.

Fino observador de la psicologia humana, Scheler pretende convertir sus hallazgos empíricos en verdades a priori sin advertir que sus observaciones mantienen la fragilidad de toda verdad empírica.

El contrasentido entre un supuesto apoyo empírico para justificar sus afirmaciones a priori resulta más patente en el caso de los cinco criterios opuestos. Comencemos por el primero: la durabilidad. ¿Qué es lo durable, el valor o el bien correspondiente? Parece claro que la jerarquía no puede depender del depositario del valor, pues la durabilidad, en tal caso, dependeria de propiedades fisicoquímicas y no del valor adscrito. Por otra parte, Scheler aclara que "los valores superiores — no los bienes - son dados forzosa y esencialmente como duraderos"."

6 Ibid., p. 134. 
Pero, ¿́cómo pueden ser más o menos duraderos los valores si son atemporales por ser esencias? Scheler insiste en su afirmación: "los valores inferiores de todos son, a la vez, los valores esencialmente 'fugaces'; los valores superiores a todos son, al mismo tiempo, valores eternos". 7 Si bien habla de los valores, Scheler parece hacer descansar la durabilidad en la naturaleza de la vivencia. "A quienquiera -escribe-, cuando quiera y por todo el tiempo que quieran ser dadas esas vivencias, siempre son dadas como 'duraderas' o 'cambiantes'. Cuando las vivimos - sin tener que esperar la experiencia de una duración fáctica-, vivimos ya en ellas mismas una durabilidad determinada, perteneciente a su esencia." 8

La experiencia no confirma lo que sostiene Scheler. Pero él cree que no hay que esperar la experiencia de su duración fáctica. Pero, ¿qué otra clase de existencia puede tener una vivencia si no es la fáctica? Por otra parte, todo lo que sabe Scheler sobre el carácter 'fugaz' o 'eterno' de ciertas vivencias tiene su origen en su propia experiencia. Y la experiencia de otro sujeto niega sus conclusiones. ¿Por qué hemos de preferir la experiencia de Scheler frente a las de otros filósofos que tienen vivencias distintas y tan valiosas como las suyas?

Dificultades similares nos presenta el segundo criterio - la divisibilidad-, a pesar de las afirmaciones enfáticas de Scheler. "También es indudable que los valores son tanto 'más altos' - escribe - cuanto menos 'divisibles' son, es decir, cuanto menos hayan de ser 'fraccionados' por la participación de muchos en ellos." 9

La afirmación no es tan 'indudable'. El goce de un baño de mar o el placer de caminar por el campo en un bello día de primavera, después de un invierno severo, tienen baja jerarquía en la escala de Scheler y, sin embargo, ni el bien ni el valor es divisible, ni hay que 'fraccionar' nada; se lo puede compartir con miles de personas como se comparte el goce musical, que pertenece a una jerarquía mucho más alta.

Aquí hay que plantear nuevamente los interrogantes que presentamos frente al primer criterio. ¿Se trata de la divisibilidad del bien o del valor? Parece claro que se refiere al valor por analogía con el primer criterio. Pero el valor, en tanto esencia, es inextenso - cualquiera que sea su jerarquía$y$, por lo tanto, no se puede dividir.

El tercer criterio - profundidad de la satisfacción- adolece de los mismos defectos. En primer lugar porque se trata de una metáfora y una metáfora no se puede convertir en un criterio riguroso. Se advierte que es una metáfora al preguntarse qué sentido puede tener la 'profundidad' de un

7 Ibid., p. $13^{6 .}$

8 Loc, cit.

- Loc. cit. 
hecho psíquico que es inespacial. Bergson mostró a qué errores conducen las metáforas espaciales sobre lo psíquico que es temporal.

Por otra parte, si aceptamos la metáfora, es evidente que podemos engañarnos acerca de la supuesta profundidad de la satisfacción. Los hechos psíquicos no se dan aislados y hay satisfacciones que nos parecen 'profundas' por resonancias ajenas a la vivencia central. La experiencia nos demuestra que sujetos distintos tienen grados diversos de satisfacción frente a una vivencia similar. Hay casos en que el propio sujeto ofrece esa diversidad. ¿̨Cómo podemos resolver los conflictos de 'profundidades' de satisfacción?

De los cinco criterios, el de la fundamentación ofrece más consistencia por su carácter lógico. El propio Scheler reconoce la fragilidad de los cuatro primeros criterios, incluyendo la fundamentación. "Pero estos criterios no pueden expresar el último sentido de la altura de un valor, por más que descansen siempre en conexiones de esencias." 10

El último criterio es el de la relatividad. Scheler le adjudica la máxima importancia. "Es, pues, la característica esencial -y más primitiva- del 'valor más alto', la de que es éste el valor menos 'relativo'; y la característica esencial del valor 'más alto de todos', la de que es el valor 'absoluto'. Las otras conexiones de esencia se basan todas sobre ésta." 11 Había aclarado anteriormente "que es una conexión de esencias, el que sean dados 'como más altos' en la intuición inmediata, aquellos valores que en el sentir y preferir mismos (no a través de la reflexión) son dados como los valores más próximos al valor absoluto. Existe un percibir sentimental inmediato de la 'relatividad' de un valor, independientemente por completo del 'juicio' y la 'reflexión" ".12

Como se puede advertir, la jerarquía depende -a través de la relatividad- del percibir sentimental. O, dicho en otras palabras, la naturaleza del objeto de su modo de captación. Pero el modo de captación que sugiere Scheler parece ser privilegio de un grupo reducido de iniciados, pues hay muchas personas, del mismo nivel cultural de Scheler, que afirman no tener esa capacidad de captación y cuando creen tenerla no coincide con la de Scheler. El carácter infalible de ese percibir sentimental es muy relativo.

Por otra parte, como la jerarquía depende de la relación con el valor absoluto, que es religioso y se ajusta a una teología de un Dios personal, se derrumba tan pronto hace crisis esa teología, como ocurrió en el pensamiento último de Scheler al que aludimos anteriormente.

Hay momentos en que algunos de los criterios propuestos por Scheler parecen funcionar. Ello ocurre cuando tomamos en consideración órdenes axiológicas de niveles muy distintos, como pueden ser el placer y la justicia.

10 Ibid., p. 141.

11 Ibid. p. 145.

12 Ibid., p. 143. 
No sucede lo mismo cuando las diferencias son pequeñas, como es el caso de los valores espirituales. ¿Qué es superior, la belleza, la justicia o la verdad como valor de conocimiento puro? ¿Qué criterios podemos usar para ordenar estos valores jerárquicamente? Tanto la preferencia como los cinco criterios pierden aquí la poca fuerza que tenían. Pero los conflictos axiológicos se producen justamente cuando las diferencias no son muy notables y en esos casos es cuando más necesitamos de criterios esclarecedores.

El rápido examen que hemos hecho de los cinco criterios nos permite concluir que ellos no son suficientes para determinar una jerarquía inmutable y vertical como quiere Scheler. El fracaso no radica, desde luego, en que él no fuera capaz de hallar los criterios apropiados, sino en que buscaba lo imposible. En vano se intentará hallar un criterio para justificar una jerarquía como la propuesta por Scheler. Afirmar la existencia de un orden jerárquico independiente de la realidad, inmutable y a priori, es el error inicial y básico de Scheler. Tal error se halla conectado a la concepción de un valor inmutable e independiente de la realidad.

Lo ocurrido a Scheler, que funda toda la axiología en un apriorismo que se apoya en una concepción de un Dios personal, infinito y omnipotente, debe hacernos meditar sobre la doble pretensión de una teología como fundamento y del apriorismo como solución de problemas que, por su índole, tienen carácter empírico. Las observaciones de Scheler que mantienen validez son aquellas que extrajo de su rica experiencia y de su profunda capacidad de observación de la vida humana. Pero fue vana su pretensión de convertir en verdad inmutable lo proveniente de la inducción empírica.

El pensamiento filosófico parecería estar condenado a moverse como el péndulo, de un extremo a otro. Los supuestos elementos positivos de una posición hacen pie en los errores de la posición opuesta. Así, a un pensamiento apriórico, objetivo y absolutista, le sucedió en época más reciente un subjetivismo relativista y estrechamente empírico. Como el apriorismo objetivista de Scheler y Hartmann parece haber desaparecido del escenario filosófico actual, dedicaremos más tiempo a la crítica del subjetivismo que parece ser la doctrina predominante en amplios círculos de Europa y Norteamérica.

\section{El valor como placer o deseo}

El subjetivismo es, desde luego, muy anterior a Scheler: la axiología nace con una posición subjetivista con Meinong y Ehrenfels. Y aún antes de ellos, Hobbes, Hume y Spinoza sostuvieron una posición subjetivista. Escribe Hobbes en el Leviatán, primera parte, cap. 6: "Lo que es objeto del apetito o el deseo del hombre es lo que Ilama bueno; y el objeto de su odio o adversión, malo." Hume sostiene algo similar. "Cuando se afirma que una acción o 
persona es vil, sólo se quiere decir que, debido a la constitución de nuestra naturaleza, se tiene un sentimiento de rechazo cuando se la contempla." 13

Spinoza es aún más explícito en la Etica, III, prop. IX, escol., donde escribe: "Jamás nos esforzamos, deseamos o aspiramos algo porque lo consideramos bueno sino que, al contrario, consideramos que algo es bueno porque nos esforzamos, deseamos o aspiramos a él."

Cuando el problema axiológico se planteó en forma sistemática, la primera respuesta que se ofreció (Meinong) fue reducir el valor al placer que produce. Pero, ¿es cierto que los valores estéticos o morales pueden reducirse al placer? Si bien en algunos casos la belleza y el placer pueden estar unidos, ¿es algo bello porque produce placer? ¿O es justamente lo opuesto, que la belleza es la que nos causa el placer que experimentamos?

G. E. Moore asestó un duro golpe al hedonismo y a todas las doctrinas naturalistas en su hoy famoso argumento de la 'falacia naturalista', expuesto en 1903 en Principia Ethica. Si bien no hay acuerdo acerca de lo que entendía Moore por 'falacia naturalista', pues usa la expresión para refutar posiciones muy diversas, parece claro que se comete la falacia naturalista cuando se define 'bueno' en términos de una propiedad natural. William E. Frankena intentó reducir la falacia naturalista a falacia definitoria (definist fallacy) y hay muchos filósofos que han querido esquivar la fuerza del argumento de Moore.

Otro argumento muy fuerte de Moore contra las interpretaciones naturalistas del valor es la llamada 'cuestión abierta' (open question). Después que nos han enunciado todos los caracteres descriptivos de un objeto que se considera bueno, cabe aún preguntar: ces realmente bueno? Si nos dicen que un objeto es placentero podemos preguntar: ¿es bueno?

Este argumento no es la única razón que tenemos para rechazar la reducción del valor a placer. La razón principal es el hecho de que hay cosas que son valiosas y no son placenteras y otras que son placenteras y no son valiosas. Es evidente que hay cosas que tienen ambas propiedades.

Ésta es una cuestión empírica que sólo los hechos pueden decidir. A menos que se estire la noción de 'placentero' a un extremo injustificado, ¿puede afirmarse que una tragedia de Sófocles o Shakespeare es placentera?

Hay personas que al ver ciertas obras de elevada intensidad dramática sufren desagradables trastornos de orden fisiológico y psicológico. No se trata de seres anormales; muchos pertenecen al grupo de personas de fina sensibilidad estética. No van a ver esas obras para tener un goce placentero; si tal fuera la intención irían a ver una comedia musical o algo similar. La literatura, la música, la pintura, nos ofrecen cientos de ejemplos ilustres de obras que no fueron creadas para suscitar placer, sino una vivencia más profunda y conmovedora.

13 Treatise of Human Nature, ed. Selby-Bigge, III, I, sec. I, p. $4^{68 .}$ 
Lo mismo se puede afirmar en el plano moral. ¿Quién puede tener placer de lanzarse, en invierno, a un río helado y peligroso para salvar la vida a un desconocido? En tales casos, el valor moral de la acción no depende para nada del placer que provoca.

Vemos el caso opuesto: algo que produce placer y no es valioso. De nuevo la literatura ofrece una gama muy amplia de obras placenteras y de escaso o nulo valor estético, como ocurre con la mayoría de las comedias musicales o las obras pornográficas.

Algo similar sucede en el plano moral. Una persona con una familia muy numerosa que gasta el poco dinero que tiene en bebidas alcohólicas o drogas puede lograr grandes placeres; nadie juzgará, sin embargo, que se trata de una buena acción moral.

Se ha intentado salvar la teoría hedonista distinguiendo distintos estratos de placer. La distinción exige un nuevo elemento cualitativo, pues no basta la cantidad o intensidad del placer. $Y$ ese nuevo elemento cualitativo, que no es reducible a placer, es lo fundamental.

No son éstas las únicas dificultades que ofrece la teoría hedonista. Puede uno preguntarse, ęel placer de quién? La experiencia reiterada muestra que una cosa puede producir placer a una persona y dolor a otra. En casos de conflicto, ¿cuál reacción debe predominar? Estos conflictos son comunes, tanto en el orden estético como en el moral. Una buena teoría axiológica no sólo debe explicar la naturaleza del valor, sino proveer criterios adecuados para resolver conflictos de valores. Si la única solución que se ofrece es el placer, y la cantidad de placer no soluciona el problema, la teoría es defectuosa.

El placer es un estado psicológico; en sí mismo no es bueno ni malo. Su bondad o maldad se debe a la referencia a un valor, un fin o una norma. Por lo tanto, cuando sabemos que algo es placentero, no sabemos nada sobre su calidad axiológica.

Una segunda interpretación naturalista del valor es equipararlo con el deseo. Filósofos de alto rango, desde Christian von Ehrenfels hasta Bertrand Russell creen que algo es valioso si lo deseamos.

Esta doctrina es superior a la anterior. Es verdad que deseamos la buena literatura o la música y que lo mismo ocurre con instituciones y personas. Este hecho innegable ¿nos permite concluir que el valor equivale al deseo? Desde luego que no. Como señalamos en el caso del placer, hay cosas que deseamos y que no son buenas y otras que son buenas y no deseamos. También el 'deseo' necesita de un agregado cualitativo, como 'bueno', 'adecuado', 'correcto', etc. $\mathrm{Y}$ estos adjetivos no se pueden extraer del deseo como estado vivencial.

Cuando el deseo y lo valioso van juntos podría ocurrir que deseamos algo porque es valioso y al revés. La conocida distinción entre 'deseado' y 
'deseable' muestra que la cualidad axiológica no puede reducirse a la presencia de una vivencia. Hay cosas que no deseamos y qué son deseables y otras en las que ocurre exactamente al revés. El deseo es un estado psicológico que se mueve por resortes psicológicos, cuando no fisiológicos. Cambios interiores del sujeto, que en nada afectan a la calidad del objeto, modifican nuestros deseos. Una dosis de alcohol altera nuestros deseos y preferencias, y sería absurdo medir la calidad estética de una obra de arte o el valor moral de un acto por la cantidad de alcohol que ingiere el sujeto.

Del mismo modo como nuestros deseos no pueden convertir en útil algo que sea inútil, tampoco pueden convertir en buena una acción mala o en bello un cuadro feo.

También en este caso podemos preguntarnos, ¿el deseo de quién? El desacuerdo o conflicto de deseos es frecuente. ¿Cómo podemos resolver esos conflictos? ¿Cuál es el deseo que debe prevalecer? Lo mismo que ocurría con el placer, no puede predominar el deseo más intenso, pues la 'intensidad' puede depender de factores psicológicos y fisiológicos accidentales que nada tienen que ver con la calidad del objeto.

Tanto en el 'deseo' como en el 'placer'; la falacia no consiste en la reducción del valor a una propiedad natural, sino a un estado psicológico. Si bien el valor no puede aislarse de nuestras reacciones psicológicas, no es menos cierto que no se lo puede reducir a tales reacciones. Lo que hace que unobjeto o persona sea deseable es una cualidad o serie de cualidades, que se hallan en el objeto, aunque en relación con un sujeto. Son esas cualidades las que llaman nuestra atención y suscitan nuestro deseo e interés.

Y a ellas se debe la 'deseabilidad' del objeto. La 'deseabilidad' no es una esencia, depende del conjunto de las cualidades empíricas del objeto.

\section{El valor como interés}

La doctrina del interés es el tercer intento importante de reducir el valor a una cualidad natural de tipo psicológico. Ralph Barton Perry la sostuvo en su grueso volumen publicado en 1926 titulado General Theory of Value; insistió en la misma interpretación veintiocho años después en su obra Realms of Value.

Según Perry, "lo que es objeto de interés adquiere eo ipso valor. Un objeto, de cualquier clase que sea, adquiere valor cuando se le presta un interés, de cualquier clase que sea; del mismo modo que una cosa se convierte en blanco (target) cuando cualquiera apunta (aims at) a él". ${ }^{14}$ Agrega que su doctrina puede también formularse en la ecuación: " $x$ es valioso $=$ se ha tomado interés en $x^{\prime \prime} .{ }^{15}$

14 General Theory of Value, Cambridge, Mass., Harvard University Press, 1950, $2^{\mathrm{a}}$ ed., pp. $115-116$.

15 Ibid., p. 116. 
La misma doctrina se encuentra reiterada en Realms of Value donde escribe: "una cosa -cualquiera que sea- tiene valor, o es valiosa, en un sentido original y genérico, cuando es objeto de un interés, cualquiera que sea. $O$, lo que es objeto de interés es ipso facto valioso". ${ }^{16}$

El punto débil de la doctrina de Perry no radica en que haya escogido el interés en lugar de otro estado psicológico, sino en el intento de reducir el valor a nuestra reacción psicológica. Enfrenta, por lo tanto, dificultades similares a las que señalamos en el caso del placer y el deseo. Tendremos que formularnos las mismas preguntas: đel interés de quién? $\mathrm{Y}$ si se responde el interés de cualquiera, como parece surgir de la doctrina de Perry, habrá que reiterar la pregunta: ¿cómo se resuelven los conflictos de intereses?

No hay duda de que existen conflictos de intereses; basta leer los diarios para advertirlo. Hay casos en que el conflicto de intereses se da en la propia persona. Entonces pensamos, deliberamos, analizamos las razones a favor o en contra de cada posibilidad antes de decidirnos. Ello demuestra que no basta el mero interés, sino que debemos atender también a las características objetivas de cada posibilidad. Si bastase el interés dejariamos que prevaleciera el más fuerte que, por definición, sería el correcto. Pero al interés, impulso y deseo interior le oponemos razones, y muchas veces frenamos nuestro interés o lo desviamos deliberadamente hacia objetos que son más interesantes.

El interés, lo mismo que el placer y el deseo, o cualquier otro estado psicológico necesitan un adjetivo: bueno, malo, adecuado, noble, bajo, etc. Este adjetivo califica - valora- al interés y no puede derivarse de una cualidad natural.

Lo señalado no implica que las reacciones psicológicas, como el interés, deban ser dejadas totalmente de lado. No son tan sólo modos de descubrir el valor de un objeto; en muchos casos forman parte de la constitución del valor. Un objeto no podría tener valor a menos que existiera la posibilidad de que alguien, en algún momento, se interesara en él. Pero el interés constituye tan sólo un aspecto de la cuestión. El otro lo forman las cualidades del objeto que son capaces de suscitar nuestro interés y que, en parte, explica que nos interesemos en ciertos objetos y no en otros. Estas cualidades convierten al objeto en 'interesante', en el sentido de merecedor de nuestro interés. Perry rechaza expresamente estas cualidades en el cap. III de su Teoria general del valor, después de analizar la posibilidad de que el valor fuera un determinado tipo de objeto (qualified object) de nuestro interés. También rechaza en el capítulo siguiente la posibilidad de que el valor sea el objeto de un determinado tipo de interés (qualified interest).

Por tratarse de un estado psicológico, el interés se puede suscitar, fortalecer o debilitar modificando las condiciones del sujeto, aunque se manten-

16 Realms of Value, Harvard University Press, 1954, p. 3. 
gan invariables las cualidades del objeto. La propaganda comercial y la politica se basan en este hecho psicológico frecuente. Los sujetos varían en sus intereses y en las razones que motivan tales intereses. ¿Podemos acaso equiparar todos los intereses? ¿Tiene el interés de un niño o un anormal la misma jerarquía que el de una persona madura, normal y educada?

Una de las características de una personalidad infantil radica en el tipo de intereses que tenga y las razones de esos intereses. A medida que crecemos espiritualmente y nos educamos, nuestros intereses cambian. Lo mismo ocurre con el anormal; la cura puede consistir en cambiar el repertorio de sus intereses.

Como se puede advertir, la clase de intereses y las razones que los motivan son muy importantes. Ello prueba que el interés, por sí mismo, no es suficiente. Debemos saber de qué clase de interés se trata y para ello hay que prestar atención a las cualidades del objeto.

Veamos otros argumentos contra la identificación dèl valor con el interés.

¿Qué interés puede tener una persona en algo cuya existencia ignora? Tal es el caso de piezas arqueológicas que aún no han sido descubiertas. Supongamos que se las descubra por casualidad y se trate de piezas de valor dispar. ¿Por qué se interesa el arqueólogo en unos objetos más que en otros? Sencillamente porque encuentra en ellos cualidades que están ausentes en los otros. El valor estético o histórico no depende de mi interés personal. Mi interés en una pieza por haberla descubierto no le confiere valor, ni siquiera ante mis propios ojos, especialmente si soy arqueólogo.

El objeto puede aumentar de valor cuando se descubre que posee cualidades que no conocíamos. Veamos el caso del valor nutritivo de los alimentos. ¿Depende de mi interés o de su constitución bioquímica? Es evidente que mi interés no puede convertir algo venenoso en alimenticio.

Puedo tener interés en un objeto por estar mal informado sobre sus cualidades. Cuando descubro la verdad, mi interés desaparece; ello muestra que el valor del objeto que había suscitado mi interés depende de cualidades objetivas y no de mi estado psicológico. Un interés basado en un error no puede convertir un objeto en valioso. Por eso hablamos con frecuencia de intereses adecuados e inadecuados, nobles y bajos.

Perry no lo cree así. Escribe: "El objeto de un interés adecuado no es ipso facto mejor que el objeto de un interés indebido. Porque mejor, lo mismo que bueno, depende de lo que le ocurre al interés, pues de éste deriva el objeto su valor y no de los juicios correspondientes" ... "Los temores infundados que ridiculizaba Epicuro no dejaban de ser temores por ser infundados" ..."Si queremos ser coherentes con nuestra definición, debemos estar dispuestos a afirmar que los objetos de tales intereses no son menos valiosos porque el interés sea errado." 17

17 General Theory of Value, p. 614. 
Perry tiene razón en lo que se refiere a la vivencia llamada interés. El interés, como estado psicológico, es tan interés cuando tiene o carece de fundamento. Pero si se refiere al vạlor de un objeto la situación varía. ¿Cómo puede ser valioso un objeto si nos hemos interesado en él debido a cualidades que le adjudicábamos y de las que realmente carece? Si valoro una herramienta porque creo que es capaz de realizar determinada función cuando no es así, soy víctima de una ilusión axiológica basada en un error empírico y mi interés, no importa cuán intenso sea, no será capaz de convertir en útil lo que es inútil.

La propaganda de mala fe de ciertos productos consiste en despertar interés en cosas que carecen de valor. Si el interés, aunque infundado, fuera capaz de convertir un objeto en valioso, la inmoralidad del engaño en la propaganda de mala fe carecería de sentido. Tiene pleno significado porque el valor de un producto no depende de nuestro interés sino de las cualidades del objeto al que se refiere.

Si se toma en consideración tan sólo nuestro interés y no las cualidades objetivas de algo valioso, jamás podríamos cometer un error en la evaluación. Podríamos equivocarnos tan sólo acerca de nuestro propio interés: creer que nos interesa algo que realmente no nos interesa. Se trata, en tal caso, de un error empírico, acerca de un hecho y no de una evaluación. Si uno se interesa realmente en un objeto inútil y el interés está basado en la ignorancia, el error o en razones infantiles o tontas, el objeto es, sin embargo, eo ipso valioso, según Perry. Pero si no existe el error, tampoco existirá la verdad, pues se trata de dos nociones que tienen sentido con referencia a la otra.

Si el interés confiere valor a un objeto, tan pronto cesa, el valor desaparece. Supongamos que dejan de interesarnos los clásicos de la literatura y en cambio nos interesan las novelas radiales. Los clásicos pierden valor y las novelas radiales lo adquirirán, al menos hasta que nos interesemos nuevamente en los clásicos. La teoría parece suponer que nuestro interés actual en los clásicos es arbitrario o se debe al azar, y no a las cualidades que encontramos en tales obras. Si así fuera, toda la educación carecería de sentido.

Examinemos el problema referente al conflicto de valores. Perry no es ciego a tales conflictos e intentó resolverlos por medio de su teoría de la "conmensurabilidad de los valores" y los tres criterios que propone: intensidad, preferencia y amplitud (inclusiveness). El principio generaI es muy sencillo. Si "es el interés el que confiere valor a un objeto, debe ser el interés el que confiere el grado de valor. El principio tiene validez para cualquiera definición del valor genérico. Si lo bueno equivale al placer y lo malo al dolor, lo mejor corresponde a mayor placer y lo peor a mayor dolor". 18

La idea de "conmensurabilidad" tal cual la concibe Perry no está exenta de dificultades. ¿Podemos medir y comparar intereses de clases distintas? Mi

18 Ibid., pp. 599-600. 
interés en la filosofía es distinto a mi interés en el tennis. Del mismo modo, mi interés en la educación de mi hijo es distinto al interés que tengo en la educación de mi perro: Si se trata de intereses de especie distinta, ¿podemos reducirlos a una unidad común y sumarlos, restarlos y multiplicarlos?

Perry pretende derivar la noción de 'cantidad' de valor del uso de "términos tales como 'mejor', el 'mejor', 'peor', el 'peor', 'más alto', 'más bajo', 'superior', 'supremo', que implican claramente 'más', 'lo máximo', 'menos', 'lo mínimo', en algún sentido". ${ }^{19}$ No advierte que son metáforas del habla común y que no se puede cuantificar una metáfora.

La falacia de la reducción del valor al grado de interés y el intento de lograr una unidad común para medir los valores se advierte claramente en el criterio de 'intensidad' que propone Perry. Deja de lado, en tal caso, las profundas diferencias de tipos de intereses y valores. Comparemos, por ejemplo, estos cuatro tipos de intereses en una obra filosófica: a) la del autor de la obra; b) la de un estudiante que tiene que leerla para aprobar un examen; c) la de la esposa del autor; y d) la del librero. Estos cuatro intereses pertenecen a clases distintas y van de un interés intelectual a uno meramente económico.

Perry no repara en estas diferencias para prestar atención solamente a la intensidad del interés. En nuestra opinión, la clase de interés y las razones que lo motivan son más importantes que la 'intensidad' de la vivencia, que puede haber adquirido un mayor grado por razones psicológicas circunstanciales y pasajeras.

Si pasamos del primero al segundo criterio - preferencia--, podemos advertir las dificultades que surgen del intento de hacer depender la jerarquía del grado de interés. El librero puede preferir Superman a El Quijote porque se vende más. Esa preferencia, clo convierte en una mejor obra? Una persona puede preferir un Impala a un Ferrari porque es más grande o porque cree, erróneamente, que es un auto más veloz. ¿Puede una preferencia basada en razones irrelevantes o en errores de hecho superar preferencias bien fundadas, como parece implicar el criterio que propone Perry?

A pesar de que con sus tres criterios intenta resolver los conflictos de intereses y también los conflictos entre los propios criterios, Perry se ve obligado a admitir que hay casos en que no se llega a tal solución. Escribe: "Nos vemos forzados a concluir, por lo tanto, que es insoluble el problema de la magnitud comparativa de los intereses en conflicto que tienen igual intensidad, y que es imposible juzgar que uno de los objetos sea mejor o peor que el otro. La pregunta, ‘ ¿es mejor, en términos absolutos u objetivamente, que este interés deba prosperar a expensas de aquel otro, o aquél a expensas de éste?, no tiene respuesta en términos estrictos. Una alternativa es mejor relativamente al primer interés y la otra mejor relativamente al segundo

19 Ibid., p. 626. 
interés; no se puede afirmar que una de las dos sea mejor en términos globales." 20

En el caso de la preferencia admite nuevamente la imposibilidad de resolver algunos conflictos de interés. Dice que si "dos preferencias se mantienen en conflicto, enfrentamos dos hechos indiscutibles y ambas partes deben aceptarlos, esto es, que mientras yo prefiero $b$ a $a$, usted prefiere $a$ a $b$. Tal conflicto de preferencia, lo mismo que los conflictos de intereses, es un dato referente al valor y un ejemplo de su relatividad última e irreductible". ${ }^{21}$

¿Puede ser ésta la conclusión de una teoría axiológica? ¿Qué ocurre cuando las preferencias se refieren a hacer o dejar de hacer algo? La acción no puede esperar a que la perplejidad del filósofo se disipe.

Las dificultades que enfrenta Perry derivan del hecho de que el interés no basta para que algo se convierta en bueno o valioso y, menos aún, para que se convierta en mejor. El interés puede estar motivado por factores que nada tienen que ver con la cualidad del objeto. Del mismo modo, nuestras preferencias no modifican la situación. Hay intereses y preferencias infantiles, tontas y perversas.

Si bastase el mero interés, la educación carecería de sentido. En el caso de la enseñanza de las humanidades, la educación consiste en motivar el interés de los estudiantes por obras que son interesantes; suscitar el interés por aquello que realmente es merecedor de tal interés. Lo que distingue a un niño de una persona madura, a un hombre no educado de uno que lo es, a un salvaje de una persona civilizada, a un demente de un hombre normal, es el repertorio de intereses y las razones que tiene para estar interesado en algo. Los tres criterios que propone Perry dejan de lado el aspecto cualitativo del interés y son inadecuados, por lo tanto, para explicar las diferencias axiológicas.

Es evidente, por otra parte, que el valor no puede equivaler, a un mismo tiempo, al placer, deseo o interés. $Y$ éstas no son las únicas interpretaciones 'naturalistas'. Si una de estas teorías es cierta, las otras serán erradas y no hay criterio aceptable para resolver los conflictos entre estas doctrinas.

Las críticas que hemos formulado a estas tres teorías pueden aplicarse a cualquiera otra que pretenda reducir el valor a un estado psicológico.

¿Debemos concluir de este análisis crítico que los valores nada tienen que ver con nuestras reacciones psicológicas $y$, en particular, con el placer, deseo e interés? Nada de eso. Éste fue el error de G. E. Moore. Para evitar la reducción del valor a las cualidades naturales se alejó de la experiencia y quedó atrapado en un punto muerto.

Pensó con razón que los valores no se pueden reducir a propiedades naturales, pero volvió la espalda a todo elemeno empírico y buscó la explica-

20 Ibid., pp. $654-55$.

21 Ibid., p. 640 . 
ción donde no podía encontrarla. De ahí que concluyera que el valor es una cualidad simple, indefinible, que se capta por intuición. Tuvo razón al señalar que era difícil definir al valor, pero tales dificultades no se debían, como él creyó, al hecho de que se trataba de una cualidad simple, sino más bien, a que era demasiado compleja.

Moore no quedó satisfecho con su interpretación; en varias oportunidades expresó sus propias dudas.

\section{Las perplejidades de G. E. Moore}

Si se examina el problema con detenimiento, aprovechando la contribución de Moore, se llega a la conclusión de que tanto las doctrinas que afirman que los valores dependen de las propiedades naturales, como las que sostienen que no pueden reducirse a ellas están en lo cierto. El valor no es cualidad descriptiva y, sin embargo, depende de cualidades descriptivas.

Moore llegó a una conclusión similar aunque presentada en forma poco clara. Veamos lo que afirma, pues su perplejidad es compartida por otros axiólogos y puede servirnos para deshacer algunas contradicciones. Escribe: "Dos proposiciones distintas son igualmente verdaderas acerca de la bondad (goodness), a saber: 1) que depende solamente de la naturaleza intrínseca de lo que la posee...2) que, a pesar de que esto es verdad, la bondad no es una propiedad intrínseca... Es por esto por lo que afirmamos anteriormente que si hay algún valor intrínseco debe constituir una clase de predicado que es único, pues no podemos pensar en ningún otro predicado que se le asemeje en este aspecto; que a pesar de no ser intrínseco comparte, sin embargo, con las propiedades intrínsecas la característica de depender solamente de la naturaleza intrínseca de lo que la posee. Que yo sepa, algunos predicados de valor son las únicas propiedades no intrínsecas que comparten con las propiedades intrínsecas la característica de depender tan sólo de la naturaleza de aquello que las posee." 22

Si parafraseamos a Moore, sustituyendo 'intrínseco' por 'natural' o 'descriptivo', podemos afirmar que dos proposiciones son verdaderas sobre la 'bondad' o cualquier otro valor: I) que depende unicamente de sus propiedades naturales o descriptivas; 2) que, sin embargo, no es una propiedad natural o descriptiva.

Comparto con Moore la opinión de que ambas proposiciones son verdaderas, pero extraigo una conclusión distinta. No hay duda de que la primera proposición es verdadera: la bondad depende de las cualidades naturales.

22 "The Conception of Intrinsic Value", en Philosophical Studies, Nueva York, Harcourt \& Brace, 1922, p. 273. Escribe poco más adelante: "Las propiedades intrínsecas parecen describir la naturaleza intrínseca de aquello que las posee, cosa que no ocurre con los predicados de valor". Op. cit., p. 274. Sobre el significado de 'descripción', ver la respuesta de Moore a los críticos en el volumen The Philosophy of G. E. Moore, editado por Paul A. Schilpp. pp. 590-92. 
La verdad de la segunda proposición se deriva del hecho de que hay ciertos conjuntos de cualidades naturales capaces de producir una cualidad axiológica, como la bondad o la belleza, que dependen de las cualidades naturales, pero que no pueden reducirse a ellas. Si así fuera, las cualidades naturales o descriptivas serían una condición necesaria pero no suficiente del valor. Los valores parecen requerir algo más, aunque no algo misterioso insuflado desde afuera. En otras palabras, debe haber alguna clase de cualidad que depende de las propiedades naturales y que al mismo tiempo no se reduzca a un mero agregado de ellas.

\section{El valor como cualidad estructural}

Creo que hay una cualidad que reúne esas condiciones: la cualidad estructural. Es empírica, aunque no 'descriptiva' o 'natural', en el sentido en que lo son los colores, sonidos, placeres y deseos para G. E. Moore.

¿Qué es una estructura? Su característica principal es que tiene propiedades que no se encuentran en ninguno de los miembros o partes constitutivas ni en el mero agregado de ellas. Por eso hay siempre novedad en una estructura auténtica. Y lo importante es el tipo de totalidad que surge de la relación de los miembros que la forman.

Una estructura depende de sus miembros, pero no equivale a la mera yuxtaposición de ellos. En muchos casos, la relación de los miembros es más importante que la naturaleza intrínseca de ellos.

El hecho de que una estructura no se reduzca al agregado mecánico de los miembros que la componen no debe hacernos pensar que se trata de un ente metafísico; es una cualidad empírica, real. Un organismo vivo, una sinfonía, una obra de teatro, son estructuras. Un drama no puede reducirse a la yuxtaposición de sus actos o escenas y menos aún a las oraciones o letras que lo forman. El sentido total es lo que cuenta.

El mundo físico ofrece también ejemplos de estructuras. La cualidad explosiva de la pólvora no se halla en ninguna de las sustancias que la forman. Una burbuja o una forma arquitectónica son también ejemplos de estructuras físicas. Pero es en el mundo psicológico y cultural donde debemos buscar las estructuras de mayor interés.

La transposición de una melodía es un ejemplo claro de que su cualidad estructural no depende sus componentes.

Transpongamos la siguiente melodía:

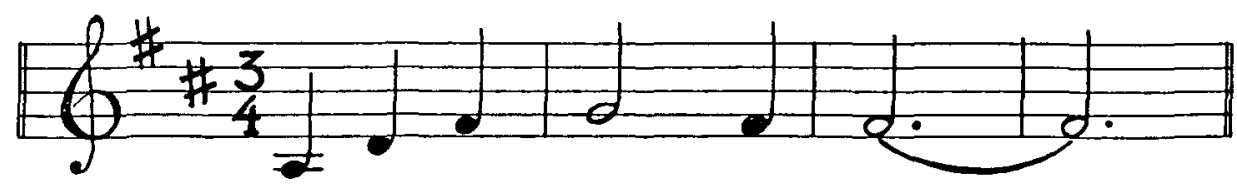

de Re Mayor a Mi bemol Mayor: 


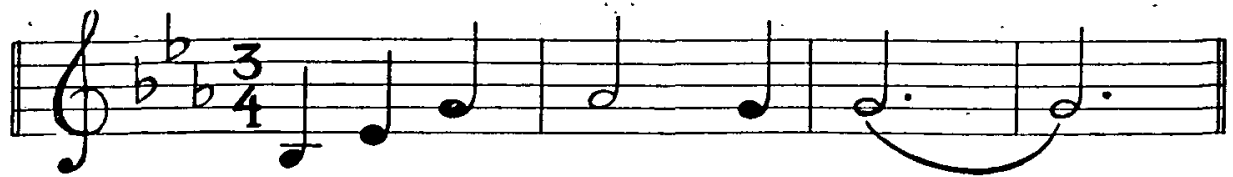

Reconoceremos inmediatamente la melodía, a pesar de que los sonidos que la forman son distintos. Ello prueba que no son los sonidos sino sus relaciones lo que constituye una estructura melódica determinada, aunque es evidente que la melodía no puede existir sin sonidos. Las estructuras son 'realidades' efectivas y no el producto de la imaginación o de la teoría filosófica.

En el mundo de habla inglesa se asocia tradicionalmente al empirismo con el análisis. Si algo no puede ser dividido y analizado en sus partes constitutivas carece de existencia para muchos filósofos. De ahí que, para algunos, el conocimiento empírico esté reñido con las totalidades porque las cualidades estructurales son irreductibles a sus componentes. No sorprende, por lo tanto, que distinguidos filósofos de habla inglesa hayan dirigido virulentos ataques a la noción de estructura, tal cual la presentamos aquí como traducción de Gestalt. Uno de ellos es E. Nagel en su ensayo "Wholes, Sums and Organic Unities" ["Totalidades, sumas y unidades orgánicas"].23

Escribe Nagel: "Tales totalidades (wholes) se caracterizan, según una afirmación repetida, por tener una organización que las torna en 'alga más que la suma de sus partes" "... "Lo primero que corresponde hacer notar es que las palabras 'totalidades' y 'suma', tal cual se las emplea comúnmente, san vagas, ambigüas y aun metafóricas." Dedica las tres páginas siguientes (pp. 136-38) a un análisis de la palabra 'totalidad' y las ocho que siguen (pp. 198-46) a los significados de 'suma'. En las pocas páginas que restan analiza las 'totalidades orgánicas' de tipo físico. Hay una sola referencia a una melodía (p. 144) en relación al ejemplo de Wertheimer y yerra en la observación.

El análisis semántico está muy bien hecho, como no era menos de esperar de un filósofo de la calidad de Nagel, pero hay dos puntos que es necesario señalar. En primer lugar, concentra el análisis en la palabra 'suma', a pesar de que podemos definir una estructura (Gestalt) sin usar ese término. En segundo lugar no podemos negar la existencia de una realidad empírica porque sean ambiguas las palabras que usamos al describirla. Si así fuera, deberíamos eliminar, por lo menos, la mitad de los estados psicológicos. Hay que prestar más atención a las estructuras que a los términos que las describen, pues, aunque la descripción no sea precisa, al menos podemos señalarlas. No hay, pues, ningún problema acerca de la existencia de las estructuras; la cuestión es saber si pueden reducirse o no a sus miembros o partes constitutivas.

Bertrand Russell es un filósofo que usó su aguda capacidad analítica para reducir la totalidad de nuestra personalidad a sus elementos constitutivos. Esa

23 Cf. Parts and Wholes, comp. por Daniel Lerner, Nueva York, The Free Press of Glencoe, 1969, pp. 135-55. 
capacidad no le impidió reconocer la existencia de las estructuras (Gestalten). Escribió: "Los fenómenos mentales, como todos los otros fenómenos, están constituidos por particulares diversamente relacionados. Las sensaciones y las imágenes son tan sólo nombres para designar estos particulares; las sensaciones son las que tienen causa próxima fuera del cerebro, y las imágenes constituyen el resto. No tengo ninguna objeción contra la psicología de la Gestalt y no siento la menor inclinación a negar que las totalidades (wholes) tengan propiedades importantes que no se deduzcan necesariamente de los elementos que las constituyen y de las relaciones entre ellos." 24

Nos parece innegable que existen estructuras (Gestalten) que no pueden analizarse sin destruirse. La insistencia en analizarlas se podría comparar a la actitud de quien arranca uno a uno los pétalos de una flor para luego sostener que ésta equivale a un montón de pétalos.

Examinemos algunos casos para ver si la interpretación del valor como cualidad estructural es adecuada.

Parece innegable que la belleza de una escultura depende de sus cualidades 'naturales': forma, color, tamaño, etc. Pero la belleza no depende de estas cualidades tomadas separadamente o al azar, sino de su interrelación. El equilibrio en la relación de las cualidades tiene tanta o más importancia que las cualidades que la constituyen. Si se rompe esa relación, la belleza desaparece.

Lo mismo puede afirmarse de la belleza de una flor. No es tan sólo el color, tamaño, forma, etc., lo que constituye su belleza, sino más bien la relación de estas cualidades. Quizá el ejemplo más adecuado sea un arneglo floral. A fin de aclarar el sentido de lo afirmado, supongamos que las flores representan las diferentes cualidades naturales. Parece claro que la belleza del arreglo floral no depende principalmente de las flores que lo forman; cuando están en una cesta o dispersas al azar sobre la mesa, no hay arreglo floral ni belleza del conjunto. Solo una disposición adecuada de las flores será capaz de otorgar belleza al arreglo. Esto es evidente si comparamos lo que puede lograr un experto con las mismas flores que un novicio ordena sin gracia. Aunque la cuestión es más compleja en pintura, la interpretación es similar.

Pasemos ahora a los valores morales. ¿Qué hace que un ser humano sea una buena persona? Se considera habitualmente que una persona es 'buena' si no miente, engaña, roba, mata, etc. Pero hay muchas personas que no cometen ninguno de estos actos "inmorales" y, sin embargo, no son buenas. Los aspectos negativos no bastan. Existe la inmoralidad de quienes no cometen ninguna falta porque no hacen nada.

Agreguemos a la 'buena' persona los caracteres positivos: ayuda al prójimo, respeta la ley, cuida de su familia, cumple con sus promesas, etc. Después de toda esta información, podemos aún preguntar: ¿es realmente una buena persona?

24 Cf. Ch. W. Morris, Six Theories of Mind, The University of Chicago Press, 1932, p. 197. 
Una persona puede ser mala a pesar de tener buenas cualidades: el balance total es lo que cuenta. Por eso hay personas que hacen cosas indebidas y son buenas, y otras que jamás violan los preceptos y no tienen ese mismo carácter. 'Bueno' y 'malo', 'bello' y 'feo' son palabras que no expresan cualidades absolutas sino grados, como ocurre con alto, gordo, sano o rico.

El ejemplo de la 'buena' persona muestra dos características de la estructura: que no se la puede reducir a la yuxtaposición de sus elementos constitutivos y que, sin embargo, depende de las partes que la forman. Por eso un cambio de una de las partes puede o no afectar la naturaleza del conjunto estructural. Supongamos haber llegado a la conclusión de que una persona es moralmente buena pues sólo tiene cualidades positivas, pero luego descubrimos que se comporta de ese modo porque lo considera más conveniente para sus intereses. Un hecho de esta naturaleza rompe la estructura constitutiva de la cualidad moral de la persona. Hay, por consiguiente, hechos relevantes y no relevantes en función del significado estructural.

Tomemos el caso opuesto: una persona que miente, roba, engaña, viola la ley, etc. Según la calificación común es una 'mala' persona. Pero luego descubrimos que se comporta de ese modo porque es el único que encontró para ayudar desinteresadamente a huérfanos enfermos y abandonados. ¿Es mala esa persona porque miente y roba? La reducción del todo a una de sus cualidades revela una mentalidad simplista. La complejidad aumentará cuando advirtamos que el conjunto estructural se da siempre en una situación determinada.

El valor no es una estructura, sino una cualidad estructural (Gestaltqualität). Una estructura es un ente, como un organismo vivo, un edificio, un poema o una persona; pero 'bello' y 'bueno' son cualidades, adjetivos. En un sentido estricto, no es correcto afirmar que el valor es una cualidad estructural, sino que la cualidad estructural es lo que hace que una cosa sea bella o buena, esto es, valiosa.

La historia de la axiología muestra el reiterado intento de reducir el valor a algo que no es. G. E. Moore acierta al citar al obispo Butler quien afirma que "cada cosa es lo que es y no otra cosa". No es ésta una afirmación trivial y deberían recordarla quienes intentan 'reducir' el valor a vivencias o esencias.

Señalamos anteriormente que la falacia de la reducción del valor a placer, deseo o interés, no se debía a que se tratase de cualidades naturales sino a que constituían sólo un aspecto del valor, esto es, el subjetivo. En el caso del deseo resulta patente: la 'deseabilidad' de lo que merece ser deseado no surge tan sólo de nuestra reacción psicológica a favor, sino de las propiedades que tiene el objeto y que lo hacen merecedor de nuestro deseo.

Tampoco se debe caer en el extremo de reducir el valor a sus cualidades objetivas. Las cualidades axiológicas surgen de la relación del sujeto con un 
objeto. El proceso es similar a lo que ocurre en el caso de la percepción de movimiento aparente. En el cine nos muestran figuras estáticas de un caballo a la carrera. Por un mecanismo psicológico, que no es el caso examinar aquí, vemos el movimiento del caballo. Es el sujeto quien agrega el movimiento, pero no lo hace arbitrariamente. En primer término están las imágenes proyectadas en la pantalla; en segundo lugar, ellas deben exhibirse a un cierto ritmo para que realmente se produzca la 'ilusión' de movimiento. Si el ritmo es muy lento vemos imágenes estáticas desconectadas.

No es, por lo tanto, el conjunto de cualidades objetivas lo que constituye una estructura en el caso del valor, sino el hecho de que esas cualidades sean percibidas por un sujeto en unas condiciones determinadas. Los pintores lo saben muy bien.

Tanto el objetivismo como el subjetivismo radical cometen el mismo tipo de error: reducir el conjunto a uno de sus aspectos. Ni proyectamos los valores ni los reflejamos pasivamente.

\section{Valor y situacion}

La relación del sujeto con el objeto no se produce en el vacío, sino en una situación física y humana determinada. No es esto algo accesorio pues afecta la relación y, por ende, el valor que surge de ella. Lo que es bueno en una situación determinada puede ser malo en otra, como ocurre con el homicidio y otros hechos generalmente negativos.

No se crea que tan sólo los grandes cambios afectan la naturaleza del valor. Desde la modificación de la temperatura hasta una guerra hay gran cantidad de cambios ambientales que afectan el valor resultante. Algunas veces los efectos no son importantes y por eso se los deja de lado.

¿Qué constituye una 'situación'? En primer lugar el ambiente físico. La temperatura, presión, clima y demás condiciones físicas afectan el comportamiento de los seres humanos y también el modo como deben comportarse, su escala de valores, etc.

Los cambios de tipo físico pueden ocurrir repentinamente, como es el caso de un huracán. Hay cosas que no se pueden hacer en momentos ordinarios, pero que están permitidas cuando sucede una catástrofe. En tales casos también se altera la escala de valores.

En segundo lugar, el ambiente cultural. Entendemos por 'cultura' todo lo que hace el hombre. Es obvio que nuestro ambiente cultural no está constituido por la totalidad de la creación de la humanidad. El sector cultural al que pertenecemos que, a su vez, forma parte de otro más amplio, es el que influye directamente.

Cada forma cultural tiene su propio conjunto de valores, aunque no sean estables sino que cambien a un ritmo que tampoco es estable. A lo largo de 
la historia han existido culturas particulares que pretendieron encarnar valores universales y tener el derecho a imponerlos a otras culturas menos fuertes. No hay razones científicas ni morales que justifiquen tal pretensión.

El medio social forma parte del ambiente cultural. Conviene reparar específicamente en él porque ejerce gran influencia en el problema axiológico. No está constituido exclusivamente por las estructuras sociales, sino también por creencias, convenciones, supuestos, prejuicios, actitudes y comportamientos predominantes en una comunidad particular, grande o pequeña. Incluye también las estructuras políticas, sociales, económicas, con sus recíprocas interrelaciones e influencias.

Los problemas morales no existen aisladamente; están enraizados en las estructuras indicadas anteriormente. La importancia de un valor moral determinado se halla condicionado por esas estructuras. No es necesario insistir en la conexión de la obra artística con el medio sociocultural.

El conjunto de necesidades, espectativas, aspiraciones y posibilidades de cumplirlas, forman el cuarto factor constitutivo de la situación. Tiene un margen muy amplio, pues va desde la escasez de ciertos productos esenciales hasta las aspiraciones. sociales y culturales de una comunidad. Este factor influye en nuestro comportamiento y condiciona nuestra escala de. valores. Si necesitamos agua y ésta escasea, su valor se eleva. No nos referimos tan sólo a su valor económico, sino a su importancia frente a otros bienes que antes eran superiores. Lo mismo ocurre ante necesidades de otro tipo, sean sociales, políticas o culturales.

Hay necesidades básicas que debemos atender antes de estar en condiciones de que surjan otras habitualmente más elevadas. Por ejemplo, un país debe alcanzar un mínimo nivel económicosocial antes de que surja la necesidad de la filosofía.

La importancia de las necesidades en una situación particular muestra cuán injustificada es la pretensión de una escala fija y permanente para toda la humanidad. Pero no sólo las necesidades y aspiraciones modifican la situación y, por lo tanto, la escala axiológica; ocurre algo semejante con las posibilidades de satisfacerlas. La evaluación moral de una persona que se abstiene de realizar ciertos actos peligrosos para salvar la vida de un niño, debe contemplar cuáles eran las posibilidades, a juicio de esa persona, de que pudiera realmente salvarlo. El riesgo exige una posibilidad mínima de alcanzar el objetivo.

El quinto elemento de la situación es el factor tempoespacial; el hecho de que nos encontremos en un lugar en un momento determinado: en Londres durante los bombardeos nazis, en un pueblo peruano en momentos en que se produce un terremoto, en Moscú durante la revolución o en un pequeño pueblito burgués en época de prosperidad. ¿Podemos aplicar la escala de valores de una anciana dedicada a hacer crochet en el tranquilo pueblito 
para juzgar la conducta de quienes vivieron las otras situaciones? Del factor espaciotemporal debemos destacar aquellos hechos que afectan directamente nuestra conducta moral o la creación artística, según el caso.

Una guerra o un huracán son ejemplos elocuentes del factor espaciotemporal de una situación. Influyen sobre nuestros modos de comportamiento y evaluación. Pero hay otros que también influyen, como el hecho de ser casado, tener hijos, estar enfermo, borracho o demente. Los atenuantes que contempla el Código Penal son otro ejemplo de la misma índole.

El factor espaciotemporal constituye lo que podríamos llamar el 'macroclima' en que ocurre un modo de comportamiento. Los hechos inmediatos relevantes conectados directamente con esa acción forman el 'microclima'. El grado de influencia de uno y otro depende de cada caso en particular.

Éstos son los factores principales, aunque no los únicos que constituyen una situación. En tiempos 'normales', la gente no advierte la presencia de los factores situacionales. Pero cuando se produce la ruptura de las condiciones 'normales', esos factores se ponen en evidencia, como ocurre en época de guerra, crisis, huracán o revolución.

Hay quienes pretenden reducir la totalidad de estos factores situacionales al predominante, sin advertir la presencia e influencia de los demás que le sirven de apoyo. Cuando se alteran las condiciones se advierte que los factores 'ocultos' estaban ahí, presentes.

Estos factores no están estratificados, como los pisos de un edificio, ni pueden ordenarse en jerarquía fija. La importancia varía según la situación total y las condiciones en que se halle el sujeto. Por otra parte, los factores están intimamente interconectados, como los órganos de un ser vivo. Cualquier cambio en uno de ellos altera los demás. Los cambios situacionales afectan la relación del sujeto con el objeto, de la que surge el valor. De ahí la importancia de la ecología del valor.

A pesar de que la conexión del sujeto con su medio es muy íntima, no debemos confundir un aspecto con el otro. Muchas de las cosas que le ocurren al sujeto son 'personales', aunque estén influidas por la situación. Algo pertenece a la situación y no al individuo cuando es compartido por otros miembros del grupo, como ocurre con la fe religiosa, la convicción política o la tradición cultural. A pesar de la íntima interrelación entre el sujeto y su medio físico, a su vez, es fácil distinguir la temperatura de nuestro propio cuerpo de la del medio en que nos hallamos.

Algo similar se puede afirmar sobre la relación entre el objeto y la situación. La situación comienza donde termina el objeto: el marco de un cuadro, la pared donde está colgado, etc. En el caso de un hecho moral, el aspecto objetivo es el hecho desnudo de la acción, y la situación es èl contexto físico y humano en que ocurrió.

Hay casos en que resulta difícil separar el sujeto de la situación, lo que 
muestra la íntima conexión entre ambos. Esto se debe a que somos seres sociales e históricos, y no individuos aislados e inmutables. En el lenguaje es donde se revela mejor este doble carácter humano: la lengua es esencialmente histórica y sirve para comunicarnos con otros miembros de la comunidad social.

Se advierte, por lo señalado, que el valor está lejos de ser una cualidad simple, como pretendia Moore. Por otra parte, no es algo que exista y que sea luego afectado por su relación con un sujeto que se halle en una situación; estos factores forman parte de la constitución del valor. Sin su presencia, el valor carece de existencia real.

Además de su complejidad, el valor también cambia, pues depende de factores cambiantes. De ahí que no haya reglas fijas para la creación o apreciación estéticas o el comportamiento moral.

Si no tomamos en consideración estos complejos cambiantes, podemos caer en algunas de las interpretaciones simplistas del valor o insistir en ajustar nuestro comportamiento moral a reglas fijas tradicionales. Uno puede ser anticuado en moralidad como lo es en la moda. Si bien el ritmo del cambio es muy distinto, ambas cambian constantemente y son el producto de complejos socioculturales. Se cae en la ilusión de valores y normas eternos porque el tiempo de observación es muy breve o por la ingenua creencia de que el momento actual, o la época histórica que se escogió como paradigma, puede perder su historicidad.

La arquitectura nos ofrece un ejemplo de cualidad estructural en una situación particular. Un buen edificio no puede reducirse a sus cualidades naturales. Su belleza, su eficiencia, etc., dependen del lugar en que fue construido, la función que se le adjudica, la reacción de la gente que lo habita, etc. Su 'bondad' es el resultado del conjunto de factores positivos y negativos que ofrece. Por ejemplo, si se trata de vivienda para familias de bajos ingresos, el costo es muy importante, cosa que no ocurre con un palacio. La conexión de estos factores con el medio físico y social es evidente. Un buen templo en Nueva York es distinto a uno en Karthum, no sólo por las diferencias de tipo climático sino también por razones religiosas, económicas y culturales.

Otro ejemplo de una cualidad estructural que depende de una situación es algo cómico o un simple chiste. Un buen chiste pierde comicidad cuando no es oportuno, porque no encaja en la situación. A su vez, para captar el sentido de algo cómico es menester estar familiarizado con el medio sociocultural. El aspecto cómico surge generalmente del contraste de elementos constitutivos de la situación. Todo lo jugoso de un chiste se pierde si es necesario explicarlo a quien desconoce el contexto.

Quizá sea conveniente señalar ahora algunas de las ventajas de una interpretación del valor como cualidad estructural. 
En primer lugar, mantiene la relación imprescindible con la realidad. No hay necesidad de suponer un reino de esencias inmutables para entender la naturaleza del valor. El valor es una cualidad empírica, producto de cualidades naturales, aunque no reducible a ellas.

Su complejidad se explica por la cantidad y variedad de factores que intervienen en su constitución. Lo mismo ocurre con su carácter cambiante. Parece extraño comprobar que la creación artística y el comportamiento humano son cambiantes y postular, al mismo tiempo, un ideal único, permanente y al que tiene que conformarse la realidad. Es claro que ese ideal está forjado sobre una realidad, aunque luego haya sido hipostasiado.

Creemos que esta interpretación del valor ayuda también a resolver problemas morales. Generalmente surgen de un conflicto de valores, en algunos casos entre dos o más valores positivos. Si siempre tuviéramos que escoger entre un valor positivo y uno negativo, entre 'bueno' y 'malo', no habría ningún problema moral. Podría haber dificultades psicológicas por tener que hacer algo que no nos agrade o no nos convenga, pero es evidente que debemos optar por lo 'bueno'.

Los conflictos morales profundos y dramáticos surgen entre dos valores positivos, entre dos obligaciones morales que atender. Las éticas tradicionales, tanto empíricas como a priori, no resuelven la cuestión, como ocurre con el imperativo categórico. Hay casos en que se pueden universalizar ambas normas contradictorias y el 'querer' tiene la misma fuerza.

La tradición ha insistido en que 'no debemos mentir' y 'debemos ayudar al prójimo'. ¿Qué ocurre cuando mentir es el único medio de ayudar al prójimo que se halla en peligro? Las éticas normativas tradicionales no proveen la vara para medir sus propias normas.

$\mathrm{Si}$ interpretamos el valor como cualidad estructural, advertimos desde un comienzo la complejidad de los conflictos morales y la imposibilidad de una receta universal para resolverlos. Ello no quiere decir que no tengan solución, sino que varía según la situación en que se halle el sujeto. Es él quien debe buscarla sin pretender aplicar mecánicamente una fórmula estereotipada. Si bien los valores dependen de la situación en que se halle el sujeto, en cada caso hay una solución moralmente superior a otra, que no depende de la arbitrariedad del sujeto. No hay que confundir 'objetividad' y 'racio nalidad' con una supuesta 'universalidad'. Cuando existe un conflicto entre dos o más valores positivos, debemos preferir el superior. Entre la verdad y la conveniencia debemos optar por la verdad; entre la justicia y el agrado debemos optar por la justicia.

No ha de creerse que exista una tabla axiológica fija que podamos consultar sin reparar en la situación en que nos hallamos, como pretendía Scheler. Pero en cada situación particular se podrá determinar cuál es el superior, previo análisis cuidadoso de los distintos factores relevantes. Lo que aumenta 
la dificultad de la tarea es que, a veces, no se trata de un conflicto entre dos valores, sino entre dos conjuntos de valores, si bien uno predomina.

Hay que tener cuidado de no pasar de un ingenuo universalismo inmutable, que pretende resolver todos los problemas morales con una cartilla de normas, al escepticismo que renuncia a toda solución al chocar con las primeras dificultades. O que cree que no existen normas morales al comprobar que no son universales y fijas.

El frecuente desacuerdo en ética y estética se explica igualmente por la complejidad de los correspondientes valores. El desacuerdo entre dos personas sobre cuál es la actitud correcta frente a un problema moral concreto, puede depender de una de las siguientes razones:

a) Una de las personas no repara en una de las cualidades naturales relevantes;

b) Una adjudica más importancia que la otra a una de esas cualidades;

c) Una no presta atención a la totalidad de las cualidades, sino tan sólo a una de ellas;

d) Difieren en lo que constituye 'fondo' y 'figura' en la estructura global; lo que es 'fondo' para una es 'figura' para la otra. Si hay un choque entre nuestro deber como universitario y el que tenemos como miembro de un partido político, el conflicto puede surgir porque una pone en primer plano el deber universitario y la otra el político.

El desacuerdo, que se usa habitualmente como argumento contra la existencia de una solución 'objetiva' y 'racional', se debe a la complejidad de los factores, al apresuramiento en llegar a una solución y a las interferencias emotivas que generalmente acompañan nuestras valoraciones morales y estéticas.

Si los conflictos morales son el resultado de un conflicto entre valores, se advierte la significación ética que adquiere la axiología. Intentamos mostrar en otro trabajo ${ }^{25}$ que hay un valor detrás de cada norma y que, por lo tanto, a una axiología situacional le corresponde una ética situacional.

La interpretación del valor que proponemos puede servir igualmente para solucionar el viejo problema del ser y deber-ser. El 'deber-ser' depende del 'ser' por medio del valor correspondiente. Pero como el valor no se reduce a la suma de los hechos, el 'deber-ser', como el valor, se apoya pero va más allá de los hechos.

Si la interpretación del valor que proponemos es cierta, sólo habremos llegado a mitad del camino. Conocemos el género al que pertenece el valor (cualidad estructural), aunque desconocemos sus características específicas. Pero esto plantea nuevos y complicados problemas que escapan al propósito de este ensayo.

Risieri Fronulzi

25 "Fundamentación axiológica de la norma ética", en Actas del VII Congreso Interamericano de Filosofia, Quebec, Les Presses de l'Université Laval. 